\title{
GAMBARAN TINGKAT KEMANDIRIAN LANSIA DALAM PEMENUHAN ACTIVITY OF DAILY LIVING (ADL) DI ROJINHOME THINSAGUNO IE ITOMAN OKINAWA JEPANG
}

\author{
DESCRIPTION OF THE LEVEL OF ELDERLY INDEPENDENCE IN \\ FULFILLMENT OF ACTIVIY DAILY LIVING (ADL) IN ROJINHOME \\ THINSAGUNO IE ITOMAN OKINAWA JAPAN
}

\author{
Nanjar Widiastuti ${ }^{1}$, Tri Sumarni ${ }^{2}$, Reni Dwi Setyaningsih ${ }^{3}$ \\ Program Studi Sarjana Keperawatan Fakultas Kesehatan \\ Universitas Harapan Bangsa \\ E-mail : nanjarye18@gmail.com ${ }^{1}$, trisumarni@uhb.ac.id ${ }^{2}$
}

\begin{abstract}
Abstrak
Activity of daily living (ADL) adalah aktivitas pokok bagi perawatan diri. Activity of daily living meliputi antara lain: ke toilet, makan, berpakaian (berdandan), mandi, dan berpindah tempat. Pengkajian ADL penting untuk mengetahui tingkat ketergantungan lansia dalam rangka menetapkan level bantuan bagi lansia tersebut dan untuk menyusun rencana perawatan jangka panjang. Tujuan dari penelitian ini adalah untuk mengetahui gambaran tingkat kemandirian lansia dalam pemenuhan ADL yang tinggal di rojinhome Thinsaguno Ie Itoman Okinawa Jepang. Jenis penelitian ini adalah deskriptif observasional. Sampel dalam penelitian ini adalah seluruh lansia di rojinhome Thinsaguno Ie Itoman Okinawa Jepang sejumlah 34 responden. Penentuan sampel menggunakan teknik total sampling. Alat ukur yang digunakan adalah lembar checklist Barthel Index. Penelitian ini menggunakan analisis data univariat yang ditampilkan dalam distribusi frekuensi. Hasil penelitian menunjukan rata-rata umur yaitu 83,23 tahun dan paling dominan pada rentang umur old (75-90 tahun) yaitu $70,6 \%$. Jenis kelamin sebagian besar perempuan yaitu $64,7 \%$, tingkat kemandirian sedang dalam ADL yaitu 38,2\%. Tingkat kemandirian lansia berdasarkan umur paling dominan pada rentang umur old (75-90 tahun) dengan tingkat kemandirian sedang (29,4\%). Tingkat kemandirian lansia berdasarkan jenis kelamin paling dominan pada jenis kelamin perempuan dengan ketergantungan sedang $(23,5 \%)$.
\end{abstract}

Kata kunci: lansia, activity of daily living, tingkat kemandirian

\begin{abstract}
Activity of daily living (ADL) is a staple activity for self-care. Activity of daily living includes, among others: toileting, eating, dressing, showering, and moving places. ADL assessment is important to determine the level of dependence of the elderly in order to determine the level of assistance for the elderly and to develop a long-term care plan. The purpose of this study was to describe the level of independence of the elderly in fulfilling the ADL at rojinhome of Thinsaguno Ie Itoman Okinawa, Japan. The type of this research is descriptive observational with cross sectional approach. The sample in this research were all 34 elderly people at rojinhome Thinsaguno Ie Itoman Okinawa Japan. Determination of the sample using total sampling technique. The measuring instrument used is the Barthel Index checklist sheet. This study uses univariate data analysis which is displayed in the frequency distribution. The results showed that the average age was 83.23 years and the most dominant in the old age range (75-90 years) was 70.6\%. The gender of most of the women was $64.7 \%$, the level of independence was moderate in ADL, namely $38.2 \%$. The level of elderly independence based on age is the most dominant in the old age range (75-90 years) with a moderate level of independence (29.4\%). The level of independence of the elderly based on sex was the most dominant in the female sex with moderate dependence $(23.5 \%)$.
\end{abstract}

Keywords: elderly, activity of daily living, level of independence

Submit / Unggah : 22 Oktober 2021, Accepted : 23 Desember 2021

Website : jurnal.stikespamenang.ac.di |Email : jurnal.pamenang@gmail.com 


\section{PENDAHULUAN}

Menurut World Health Organization (WHO), lanjut usia (lansia) adalah seseorang yang telah memasuki usia 60 tahun keatas. Manusia lanjut usia adalah seseorang yang karena usianya mengalami perubahan biologis, fisik, kejiwaan dan sosial. Perubahan ini akan memberikan pengaruh pada seluruh aspek kehidupan, termasuk kesehatannya. Perubahan fisik lansia akan mempengaruhi tingkat kemandirian (Fatimah, 2010). Kemandirian lansia dalam melakukan ADL didefinisikan sebagai kemandirian seseorang dalam melakukan aktivitas sehari-hari (Kane, 1981 dalam Sari, 2013). Kemandirian lansia dapat dipengaruhi oleh pendidikan lansia, fungsi kognitif yang menurun, gangguan sensori khususnya penglihatan dan pendengaran (Heryanti, 2011). Aktivitas kehidupan harian yang dalam istilah bahasa Inggris disingkat ADL atau activity of daily living adalah merupakan aktivitas pokok bagi perawatan diri. Activity of daily living meliputi antara lain: ke toilet, makan, berpakaian (berdandan), mandi, dan berpindah tempat. Pengkajian ADL penting untuk mengetahui tingkat ketergantungan lansia dalam rangka menetapkan level bantuan bagi lansia tersebut dan untuk menyusun rencana perawatan jangka panjang (Tamher dan Noorkasiani, 2011). Penentuan kemandirian fungsional dilakukan untuk mengidentifikasi kemampuan dan keterbatasan klien, serta menciptakan pemilihan intervensi yang tepat (Kushariadi, 2009). Pemilihan intervensi yang tepat pada perawatan jangka panjang yang diberikan kepada para lansia ini juga akan mempengaruhi tingkat keberhasilan program kesehatan yang telah ditetapkan oleh suatu negara. Keberhasilan program kesehatan dan pembangunan sosial ekonomi suatu negara dapat dilihat dari peningkatan usia harapan hidup (UHH) penduduk dari masing-masing negara tersebut. Menurut data statistik WHO 2010, Jepang menempati peringkat tertinggi di seluruh dunia dalam hal angka harapan hidup (laki-laki: 79 tahun, perempuan: 86 tahun). Berdasarkan data dari Biro Statistik Departemen Dalam Negeri dan Komunikasi Jepang, proporsi lansia dalam total populasi pada tahun 2019 menempatkan Jepang $(28,4 \%)$ di urutan tertinggi dunia dalam hal jumlah populasi lansianya, peningkatan jumlah penduduk lansia ini akan membawa berbagai dampak, terutama pada peningkatan angka ketergantungan. Berdasarkan pra survey yang dilakukan oleh peneliti pada bulan Januari 2020 di rojinhome Thinsaguno Ie Itoman Okinawa Jepang, dengan menggunakan skala ukur barthel index didapatkan hasil 4 dari 7 lansia memiliki tingkat kemandirian dengan hasil ketergantungan berat pada rentang skor 21-40 yang dihitung berdasarkan skor modifikasi barthel index ADL pada rentang 0100. Dimana semakin tinggi tingkat ketergantungan lansia maka semakin mahal pula biaya yang harus dibayarkan setiap bulannya kepada pihak rojinhome. Berdasarkan latar belakang tersebut maka perlu dilakukan penelitian tentang tingkat kemandirian lansia dalam pemenuhan ADL pada lansia yang tinggal di rojinhome Thinsaguno Ie Itoman Okinawa Jepang.

\section{METODE PENELITIAN}

Jenis penelitian ini adalah penelitian deskriptif observasional dengan pendekatan cross sectional. Bertujuan mendeskripsikan tentang tingkat kemandirian dan ketergantungan lanjut usia dalam pemenuhan aktivitas sehari-hari. Sampel dalam penelitian ini adalah seluruh lansia di rojinhome Thinsaguno Ie Itoman Okinawa Jepang sejumlah 34 responden. Penentuan sampel menggunakan teknik total sampling. Alat ukur yang digunakan adalah lembar checklist Barthel Index. Penelitian ini menggunakan analisis data univariat yang ditampilkan dalam distribusi frekuensi.

\section{HASIL DAN PEMBAHASAN}

Penelitian ini dilaksanakan di Rojinhome Thinsaguno Ie Itoman Okinawa Jepang pada tanggal 6- 25 April 2020. Responden dalam penelitian ini adalah seluruh lansia di Rojinhome Thinsaguno Ie Itoman Okinawa Jepang sebanyak 34 orang. Hasil penelitian dapat dijelaskan sebagai berikut:

\section{Gambaran Karakteristik Responden $\begin{array}{ll}\text { a. Karakteristik } & \text { Responden } \\ \text { Berdasarkan Umur } & \end{array}$}

Tabel 1. Distribusi Lansia Di Rojinhome Thinsaguno Ie Itoman Okinawa Jepang Berdasarkan Umur, Tahun $2020(n=34)$

Tabel 1 menjelaskan bahwa berdasarkan rentang umur WHO 


\begin{tabular}{lcc}
\hline \multicolumn{1}{c}{ Umur } & $\begin{array}{c}\text { Jumlah } \\
(\mathrm{n})\end{array}$ & $\begin{array}{c}\text { Persentase } \\
(\%)\end{array}$ \\
\hline $\begin{array}{l}\text { Elderly }(60- \\
74)\end{array}$ & 5 & $14,7 \%$ \\
Old (75-90) & 24 & $70,6 \%$ \\
$\begin{array}{l}\text { Very Old } \\
(>90)\end{array}$ & 5 & $14,7 \%$ \\
\hline Total & 34 & $100 \%$ \\
\hline
\end{tabular}

sebagian besar responden termasuk dalam kategori lanjut usia tua (old), yaitu sebanyak 24 orang responden $(70,6 \%)$. Hasil analisis menunjukan bahwa rata-rata (mean) umur responden adalah 83,23 tahun.

Hasil penelitian ini sejalan dengan data dari The Ministry of Internal Affairs and Communications Japan, tahun 2010 menyebutkan bahwa ratarata angka harapan hidup penduduk Jepang mencapai 82,73 tahun. Penelitian Demura, S., et al (2013) pada lansia yang tinggal di lembaga kesejahteraan bagi lanjut usia di kota Ishikawa, Akita, Fukui dan Gifu, juga menunjukkan rata-rata umur lansia laki-laki dalam penelitiannya yaitu 80 tahun dan rata-rata umur lansia perempuan yaitu 81,9 tahun.

Penelitian ini tidak sejalan dengan penelitian yang dilakukan Agustin (2008) di Panti Wredha Wening Wardoyo Ungaran, dimana hasil menunjukan sebagian besar lansia adalah usia 60-74 tahun (80,9\%). Peneliti berasumsi perbedaan umur lansia di Jepang dan Indonesia karena Jepang sebagai negara maju yang memiliki lingkungan higienis, masyarakat bergaya hidup sehat, serta teknologi pengobatan yang muktahir sehingga tidak heran memiliki banyak penduduk berumur panjang.

\section{b. Karakteristik Responden Berdasarkan Jenis Kelamin}

Tabel 1. Distribusi Lansia Di Rojinhome Thinsaguno Ie Itoman Okinawa Jepang Berdasarkan Jenis Kelamin, Tahun $2020(n=34)$

Hasil analisis tabel 2 dapat disimpulkan bahwa sebagian besar responden lansia berjenis kelamin

\begin{tabular}{lcc}
\hline $\begin{array}{c}\text { Jenis } \\
\text { Kelamin }\end{array}$ & $\begin{array}{c}\text { Jumlah } \\
(\mathrm{n})\end{array}$ & $\begin{array}{c}\text { Persentase } \\
(\%)\end{array}$ \\
\hline Perempuan & 22 & $64,7 \%$ \\
Laki-laki & 12 & $35,3 \%$ \\
\hline Total & 34 & $100 \%$ \\
\hline perempuan & yaitu & sebanyak 22 \\
responden $(64,7 \%)$ & Hasil ini \\
sebanding dengan hasil penelitian & hang \\
yang dilakukan oleh Demura, S., et al \\
(2013) pada lansia yang tinggal di \\
lembaga kesejahteraan bagi lanjut usia \\
di kota Ishikawa, Akita, Fukui dan \\
Gifu yang menunjukkan bahwa 75\% \\
lansia dalam penelitiannya adalah \\
perempuan. Hal ini sesuai dengan usia \\
harapan hidup untuk penduduk Jepang \\
yang menyebutkan bahwa usia \\
harapan hidup untuk perempuan lebih \\
tinggi dibandingkan laki-laki yaitu 86 \\
tahun untuk usia harapan hidup \\
perempuan dan 79 tahun untuk usia \\
harapan hidup laki-laki (WHO, 2010). \\
Biro Statistik, Kementerian Dalam \\
Negeri dan Komunikasi Jepang pada \\
tahun 2010 juga menyebutkan bahwa \\
populasi lansia yang berusia 65 tahun \\
ke atas lebih banyak didominasi oleh \\
wanita daripada pria.
\end{tabular}

2. Tingkat Kemandirian Lansia

Tabel 2. Distribusi Lansia Di

Rojinhome Thinsaguno Ie Itoman

Okinawa Jepang Berdasarkan Tingkat Kemandirian Tahun $2020(n=34)$

\begin{tabular}{|c|c|c|}
\hline $\begin{array}{c}\text { Tingkat } \\
\text { Kemandirian }\end{array}$ & $\begin{array}{c}\text { Jumlah } \\
\text { (n) }\end{array}$ & $\begin{array}{c}\text { Persentase } \\
(\%)\end{array}$ \\
\hline $\begin{array}{l}\text { Ketergantungan } \\
\text { ringan }\end{array}$ & 9 & $26,5 \%$ \\
\hline $\begin{array}{l}\text { Ketergantungan } \\
\text { sedang }\end{array}$ & 13 & $38,2 \%$ \\
\hline $\begin{array}{l}\text { Ketergantungan } \\
\text { berat }\end{array}$ & 7 & $20,6 \%$ \\
\hline $\begin{array}{l}\text { Ketergantungan } \\
\text { total }\end{array}$ & 5 & $14,7 \%$ \\
\hline Total & 34 & $100 \%$ \\
\hline
\end{tabular}


Tabel 3 menjelaskan tingkat kemandirian lansia yang tinggal di rojinhome Thinsaguno Ie Itoman Okinawa Jepang berdasarkan lembar checklist barthel index lebih dominan pada ketergantungan sedang sebanyak 13 lansia $(38,2 \%)$. Hal ini disebabkan oleh faktor kondisi sebagian lansia yang masih sehat secara fisik dan kognitif sehingga dapat melakukan kegiatan kemandiriannya sendiri ataupun dengan bantuan kecil dari para caregiver, selain itu usaha dari para lansia yang tetap ingin mempertahankan tingkat kemandiriannya tanpa ingin dibantu sepenuhnya oleh caregiver juga mempengaruhi tingkat aktivitas kemandirian para lansia.

\section{a. Tingkat kemandirian lansia} berdasarkan umur

Tabel 3. Distribusi Tingkat Kemandirian Lansia Di Rojinhome Thinsaguno Ie Itoman Okinawa Jepang Berdasarkan Umur, Tahun $2020(n=34)$

\begin{tabular}{|c|c|c|c|c|c|}
\hline \multirow{3}{*}{$\begin{array}{l}\text { Ka } \\
\text { rak } \\
\text { teri } \\
\text { stik }\end{array}$} & \multicolumn{4}{|c|}{ Tingkat Kemandirian TAEL 4} & \multirow[b]{2}{*}{$\begin{array}{c}\text { Tota } \\
1\end{array}$} \\
\hline & $\begin{array}{c}\text { Kete } \\
\text { rgan } \\
\text { tung } \\
\text { an } \\
\text { Ring } \\
\text { an }\end{array}$ & $\begin{array}{c}\text { Keter } \\
\text { gantu } \\
\text { ngan } \\
\text { Sedan } \\
\text { g }\end{array}$ & $\begin{array}{c}\text { Keterga } \\
\text { ntungan } \\
\text { Berat }\end{array}$ & $\begin{array}{c}\text { Keter } \\
\text { gantu } \\
\text { ngan } \\
\text { Total }\end{array}$ & \\
\hline & $n(\%)$ & $\mathrm{n}(\%)$ & $n(\%)$ & $\mathbf{n}(\%)$ & $\begin{array}{c}\mathrm{n}(\%) \\
)\end{array}$ \\
\hline $\begin{array}{l}\text { Um } \\
\text { ur: } \\
60- \\
74\end{array}$ & $\begin{array}{c}2(5,9 \\
\%)\end{array}$ & $\begin{array}{c}2(5,9 \\
\%)\end{array}$ & $0(0 \%)$ & $\begin{array}{c}1(2,9 \\
\%)\end{array}$ & $\begin{array}{c}5(14 \\
7 \%)\end{array}$ \\
\hline $\begin{array}{l}75- \\
90\end{array}$ & $\begin{array}{c}6(17, \\
6 \%)\end{array}$ & $\begin{array}{c}10(29, \\
4 \%)\end{array}$ & $\begin{array}{c}6(17,6 \% \\
)\end{array}$ & $\begin{array}{c}2(5,9 \\
\%)\end{array}$ & $\begin{array}{c}24(7 \\
0,6 \\
\%)\end{array}$ \\
\hline$>90$ & $\begin{array}{c}1(2,9 \\
\%)\end{array}$ & $\begin{array}{c}1(2,9 \\
\%)\end{array}$ & $1(2,9 \%)$ & $\begin{array}{c}2(5,9 \\
\%)\end{array}$ & $\begin{array}{l}5(14 \\
, 7 \%)\end{array}$ \\
\hline $\begin{array}{c}\text { Tot } \\
\text { al }\end{array}$ & $\begin{array}{c}9(26, \\
5 \%)\end{array}$ & $\begin{array}{c}13(38, \\
2 \%)\end{array}$ & $\begin{array}{c}7(20,6 \% \\
)\end{array}$ & $\begin{array}{c}5(14,7 \\
\%)\end{array}$ & $\begin{array}{c}34(1 \\
00 \% \\
) \\
\end{array}$ \\
\hline
\end{tabular}

Pada tabel 4 dijelaskan bahwa tingkat kemandirian lansia berdasarkan umur di rojinhome Thinsaguno Ie Itoman Okinawa Jepang paling dominan pada rentang umur old (75-90 tahun) dengan tingkat kemandirian sedang yaitu sebanyak 10 lansia $(29,4 \%)$. Hasil penelitian ini menunjukkan bahwa semakin tinggi usia seseorang maka akan semakin menurun kemampuan fisiknya dalam memenuhi kebutuhannya sehingga lansia akan mengalami ketergantungan dan membutuhkan bantuan orang lain dalam pemenuhan kebutuhan seharihari. Penelitian ini sejalan dengan penelitian literatur review Sato Shinobu., et al (2018) pada 25 jurnal terkait ADL pada lansia menunjukkan bahwa di usia tua, fungsi fisik, kemampuan beradaptasi dan kognitif menurun. Penelitian lain dari Yokoi T., et al (2013) pada 18 lansia demensia yang bisa berjalan didapatkan hasil bahwa kerusakan ADL yang luar biasa terlihat ketika gangguan kognitif menjadi lebih serius, sedangkan semakin bertambahnya usia maka lansia akan semakin rentan mengalami gangguan kognitif.

\section{b. Tingkat kemandirian lansia berdasarkan jenis kelamin}

Tabel 4. Distribusi Tingkat Kemandirian Lansia Di Rojinhome Thinsaguno Ie Itoman Okinawa Jepang Berdasarkan Jenis Kelamin, Tahun $2020(n=34)$ 


\begin{tabular}{|c|c|c|c|c|c|}
\hline \multirow{3}{*}{$\begin{array}{c}\text { Kara } \\
\text { kteri } \\
\text { stik }\end{array}$} & \multicolumn{4}{|c|}{$\begin{array}{c}\text { Tingkat Kemandirian TABEL } \\
5\end{array}$} & \multirow[b]{2}{*}{ Total } \\
\hline & $\begin{array}{c}\text { Kete } \\
\text { rgant } \\
\text { unga } \\
\text { n } \\
\text { Ring } \\
\text { an } \\
\end{array}$ & $\begin{array}{c}\text { Kete } \\
\text { rgant } \\
\text { unga } \\
\text { n } \\
\text { Seda } \\
\text { ng } \\
\end{array}$ & $\begin{array}{c}\text { Kete } \\
\text { rgant } \\
\text { unga } \\
\text { n } \\
\text { Berat }\end{array}$ & $\begin{array}{c}\text { Kete } \\
\text { rgan } \\
\text { tung } \\
\text { an } \\
\text { Tota } \\
\text { I } \\
\end{array}$ & \\
\hline & $\mathbf{n}(\%)$ & $\mathbf{n}(\%)$ & $\mathbf{n}(\%)$ & $\begin{array}{c}\mathbf{n}(\% \\
)\end{array}$ & $\mathbf{n}(\%)$ \\
\hline \multicolumn{6}{|l|}{$\begin{array}{l}\text { Jenis } \\
\text { Kela } \\
\text { min: }\end{array}$} \\
\hline $\begin{array}{l}\text { Pere } \\
\text { mpua } \\
\text { n }\end{array}$ & $\begin{array}{l}7(20, \\
6 \%)\end{array}$ & $\begin{array}{l}8(23, \\
5 \%)\end{array}$ & $\begin{array}{l}4(11, \\
8 \%)\end{array}$ & $\begin{array}{l}3(8 \\
8 \%)\end{array}$ & $\begin{array}{l}22(64 \\
, 7 \%)\end{array}$ \\
\hline $\begin{array}{l}\text { Laki- } \\
\text { laki }\end{array}$ & $\begin{array}{c}2(5,9 \\
\%)\end{array}$ & $\begin{array}{l}5(14 \\
7 \%) \\
\end{array}$ & $\begin{array}{c}3(8,8 \\
\%)\end{array}$ & $\begin{array}{l}2(5 \\
9 \%) \\
\end{array}$ & $\begin{array}{r}12(35 \\
, 3 \%) \\
\end{array}$ \\
\hline Total & $\begin{array}{c}9(26, \\
5)\end{array}$ & $\begin{array}{l}13(38 \\
, 2 \%) \\
\end{array}$ & $\begin{array}{l}7(20, \\
6 \%) \\
\end{array}$ & $\begin{array}{l}5(14 \\
, 7 \%) \\
\end{array}$ & $\begin{array}{c}34(10 \\
0 \%) \\
\end{array}$ \\
\hline \multirow{3}{*}{$\begin{array}{c}\text { Kara } \\
\text { kteri } \\
\text { stik }\end{array}$} & \multicolumn{4}{|c|}{$\begin{array}{c}\text { Tingkat Kemandirian TABEL } \\
5 \\
\end{array}$} & \\
\hline & $\begin{array}{c}\text { Kete } \\
\text { rgant } \\
\text { unga } \\
\text { n } \\
\text { Ring } \\
\text { an } \\
\end{array}$ & $\begin{array}{c}\text { Kete } \\
\text { rgant } \\
\text { unga } \\
\text { n } \\
\text { Seda } \\
\text { ng } \\
\end{array}$ & $\begin{array}{c}\text { Kete } \\
\text { rgant } \\
\text { unga } \\
\text { n } \\
\text { Berat }\end{array}$ & $\begin{array}{c}\text { Kete } \\
\text { rgan } \\
\text { tung } \\
\text { an } \\
\text { Tota } \\
\text { 1 } \\
\end{array}$ & Total \\
\hline & $\mathbf{n}(\%)$ & $\mathbf{n}(\%)$ & $\mathbf{n}(\%)$ & $\begin{array}{c}\mathbf{n}(\% \\
)\end{array}$ & $\mathbf{n}(\%)$ \\
\hline $\begin{array}{l}\text { Jenis } \\
\text { Kela } \\
\text { min: }\end{array}$ & & & & & \\
\hline $\begin{array}{l}\text { Pere } \\
\text { mpua } \\
\text { n }\end{array}$ & $\begin{array}{l}7(20 \\
6 \%)\end{array}$ & $\begin{array}{l}8(23 \\
5 \%)\end{array}$ & $\begin{array}{l}4(11, \\
8 \%)\end{array}$ & $\begin{array}{l}3(8, \\
8 \%)\end{array}$ & $\begin{array}{c}22(64 \\
, 7 \%)\end{array}$ \\
\hline $\begin{array}{l}\text { Laki- } \\
\text { laki }\end{array}$ & $\begin{array}{c}2(5,9 \\
\%)\end{array}$ & $\begin{array}{l}5(14 \\
7 \%)\end{array}$ & $\begin{array}{c}3(8,8 \\
\%)\end{array}$ & $\begin{array}{l}2(5 \\
9 \%)\end{array}$ & $\begin{array}{r}12(35 \\
, 3 \%) \\
\end{array}$ \\
\hline Total & $\begin{array}{c}9(26, \\
5)\end{array}$ & $\begin{array}{l}13(38 \\
, 2 \%) \\
\end{array}$ & $\begin{array}{l}7(20, \\
6 \%) \\
\end{array}$ & $\begin{array}{l}5(14 \\
, 7 \%) \\
\end{array}$ & $\begin{array}{c}34(10 \\
0 \%) \\
\end{array}$ \\
\hline
\end{tabular}

kemandirian lansia berdasarkan jenis kelamin di rojinhome Thinsaguno Ie Itoman Okinawa Jepang paling dominan pada jenis kelamin perempuan dengan ketergantungan sedang yaitu 8 lansia $(23,5 \%)$. kondisi ini mungkin lebih disebabkan oleh perbedan proporsi dan tidak terkait dengan karakterisktik jenis kelamin tertentu. Dari hasil tersebut peneliti berasumsi bahwa jenis kelamin tidak bisa dijadikan salah faktor untuk menentukan tingkat kemandirian pada lansia apabila jumlah responden berbeda, penyakit penyerta dan latar belakang sosio kulturalnya juga berbeda. Hal ini sejalan dengan penelitian Demura, S., et al (2013) pada lansia yang tinggal di Lembaga Kesejahteraan bagi lanjut usia di kota Ishikawa, Akita, Fukui dan Gifu yang melaporkan tidak ada perbedaan yang signifikan pada jenis kelamin terhadap perbedaan tingkat ADL pada laki-laki maupun perempuan, ketidak konsistenan temuan ini disebabkan oleh pengaruh jenis aktivitas mereka dan keseriusan penyakit yang diderita.

\section{KESIMPULAN}

Berdasarkan hasil penelitian dan pembahasan yang telah dipaparkan dan dijelaskan, maka dapat ditarik kesimpulan sebagai berikut :

Karakteristik lansia yang tinggal di rojinhome Thinsaguno Ie Itoman Okinawa Jepang menunjukan rata-rata umur yaitu 83,23 tahun dalam rentang umur old (75-90 tahun) yaitu $70,6 \%$. Jenis kelamin sebagian besar perempuan yaitu $64,7 \%$.

Lansia di rojinhome Thinsaguno Ie Itoman Okinawa Jepang memiliki tingkat kemandirian sedang dalam ADL yaitu 38,2\%.

Gambaran tingkat kemandirian lansia berdasarkan umur di rojinhome Thinsaguno Ie Okinawa paling dominan pada rentang umur old (75-90 tahun) dengan tingkat kemandirian sedang $(29,4 \%)$.

Gambaran tingkat kemandirian lansia berdasarkan jenis kelamin di rojinhome Thinsaguno Ie Okinawa Jepang paling dominan pada jenis kelamin perempuan dengan ketergantungan sedang $(23,5 \%)$.

Dari data penelitian ini terdapat beberapa hal yang kami sarankan bagi pelayanan keperawatan gerontik/ tenaga kesehatan khususnya di Indonesia diharapkan untuk dapat memberikan pendidikan kesehatan terhadap masyarakat khususnya bagi keluarga yang mempunyai anggota keluarga berusia lanjut mengenai pentingnya pemeriksaan tingkat kemandirian pada lansia, selain itu penting adanya untuk melakukan penjadwalan secara rutin terkait pemeriksaan tingkat kemandirian lansia untuk mengetahui pemenuhan aktivitas sehari-hari dalam rangka pemeliharaan kesehatan pada para lansia sehingga akan memudahkan tenaga kesehatan dalam memberikan pendidikan kesehatan terkait penetapan level bantuan yang harus diberikan kepada para lansia yang tinggal bersama anggota keluarganya dan bagi para lansia yang tinggal di panti jompo, pendidikan kesehatan ini juga dapat diberikan kepada para pendamping lansia sehingga diharapkan hal ini akan meningkatkan pelayanan kesehatan yang diberikan kepada para lansia.

Bagi penelitian selanjutnya Penelitian selanjutnya dapat dilakukan pada sampel lansia 
yang mewakili seluruh populasi lansia yang ada di Okinawa Jepang. Penelitian selanjutnya juga dapat dilakukan dengan membuktikan hubungan tingkat kemandirian lansia dengan menganalisa faktor-faktor lain seperti fungsi kognitif, kesehatan fisiologis dan penyakit yang diderita lansia sehingga mempengaruhi tingkat kemandirian lansia.

\section{DAFTAR PUSTAKA}

Biro Statistik, Kementerian Dalam Negeri dan Komunikasi Survei untuk tahun 2009, Kementerian Dalam Negeri dan Komunikasi47 tahun Institut Nasional Kependudukan dan Jaminan Sosial"Penduduk Perkiraan Jepang Menurut Prefektur (Heisei). Diambil dari: https://asia.nikkei.com/Politics-

Economy/From-elderly-to-superelderlyJapan-wrestles-with-demography(7 februari 2020)

Demura, Shinici, Susumu Sato, Masaki Minami dan Kohsho Kasuga. (2013). Gender and Age Differences in Basic ADL Ability on the Elderly: Comparison between the Independent and the Dependent Eldery. Journal of Physiological Anthropological and Applied Human Science. Diambil dari: https://www.jstage.jst.go.jp/browse/char/en (28 November 2020).

Fatimah. (2010). Merawat Manusia lanjut Usia Suatu Pendekatan Proses Keperawatan Gerontik. Jakarta : Trans Info Media.

Heryanti, IP. (2011). Hubungan Kemandirian dan Dukungan Sosial dengan Tingkat Stress Lansia. Bogor : Jurusan Ekologi Manusia Fakultas Pertanian Institut Pertanian Bogor. Tersedia dari http://www.repository.ipb.ac.i d/. Diakses tanggal 22 Maret 2020.

Kane, R. A., \& Kane, L. R., (1981). Assesing the elderly: a practical guide to measurement, Lexington, MA: Lexington Books

Kushariadi. 2009 . Asuhan Keperawatan Klien Lanjut Usia. Jakarta: Salemba Medika

Sato, Shinobu, Yukari Seki dan Shoko Kaneko. (2018). Research Trends in ADL Gaps for Elderly. Bulletin of Dokkyo Medical University School of Nursing. Vol.12 (2018). Diambil dari: https://www.jstage.jst.go.jp/browse/char/en (28 November 2020)
Tamher, S. Noorkasiani. Kesehatan Usia Lanjut dengan Pendekatan Asuhan Keperawatan.Jakarta : Salemba Medika, 2009

The Ministry of Internal Affairs and Communications Japan. Data status masyarakat lanjut usia Jepang tahun 2020. Diambil dari: https://www8.cao.go.jp/kourei/kihonkentoukai/k_2/pdf/ref2-1.pdf (10 Maret 2020).

Yokoi, Teruo, Okamoto Keisuke, Sakurai Sin, Nakamura Miyoko dan Mizuke Chihiro. (2013). Relationship between the Cognitive Impairment and ADL of the Elderly with Dementia.Departement of Physical Therapy, Geriatric Health Facility Elder Village Kobe-shi Japan. Diambil dari: https://www.jstage.jst.go.jp/browse/char/en (28 November 2020). 